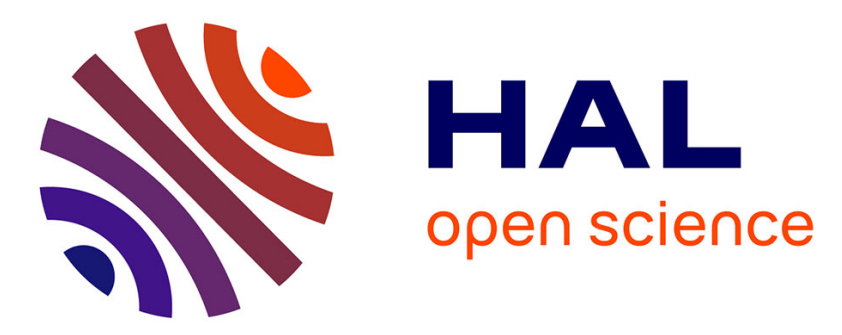

\title{
A study on the minimum duration of training data to provide a high accuracy forecast for PV generation between two different climatic zones
}

Ted Soubdhan, Minh-Thang Do, Benoît Robyns

\section{- To cite this version:}

Ted Soubdhan, Minh-Thang Do, Benoit Robyns. A study on the minimum duration of training data to provide a high accuracy forecast for PV generation between two different climatic zones. Renewable Energy, 2016, 85, pp.959-964. 10.1016/j.renene.2015.07.057 . hal-01823260

\author{
HAL Id: hal-01823260 \\ https://hal.science/hal-01823260
}

Submitted on 3 Jun 2019

HAL is a multi-disciplinary open access archive for the deposit and dissemination of scientific research documents, whether they are published or not. The documents may come from teaching and research institutions in France or abroad, or from public or private research centers.
L'archive ouverte pluridisciplinaire HAL, est destinée au dépôt et à la diffusion de documents scientifiques de niveau recherche, publiés ou non, émanant des établissements d'enseignement et de recherche français ou étrangers, des laboratoires publics ou privés. 


\title{
A study on the minimum duration of training data
}

\section{to provide a high accuracy forecast for PV}

\section{generation between two different climatic zones}

\author{
Minh Thang DO ${ }^{1 *}$, Ted SOUBDHAN ${ }^{1}$, Benoit ROBYNS ${ }^{2}$ \\ ${ }^{1}$ Laboratory LARGE, University of Antilles and Guiana, Guadeloupe, France \\ ${ }^{2}$ Laboratory L2EP, Ecole des Hautes Etudes d'Ingénieur (HEI), Lille, France \\ *Corresponding author. Address: University of Antilles and Guiana, 97159 Pointe-à-Pitre cedex, France. E-mail \\ address: mtdo@univ-ag.fr
}

$\underline{\text { Abstract: }}$

This study focus on the minimum duration of training data required for PV generation forecast. In order to investigate this issue, the study is implemented on 2 PV installations: the first one in Guadeloupe represented for tropical climate, the second in Lille represented for temperate climate; using 3 different forecast models: the Scaled Persistence Model, the Artificial Neural Network and the Multivariate Polynomial Model. The usual statistical forecasting error indicators: NMBE, NMAE and NRMSE are computed in order to compare the accuracy of forecasts.

The results show that with the temperate climate such as Lille, a longer training duration is needed. However, once the model is trained, the performance is better.

Keywords: PV forecasting models, neural network, multivariate model, forecasting errors, training duration.

1. Introduction 
With the support of environment policies and the increase of the fossil fuel price, renewable energy sources have been growing strongly in the last few years. The electric power produced by these intermittent sources shows strong variations (sudden and with large amplitude), which must be always compensated on the grid by others dispatchable sources (Ernst et al., 2009), (Do et al., 2010), (Do et al., 2011).

These large variations can put a pressure on the balance of supply/demand of the power system, especially in non-interconnected systems, such as island areas. In the case of French islands for which Island Energy System is the electrical system manager, in order to ensure the stability of the power system, a ministerial decree of 2008 set the penetration rate at $30 \%$, beyond which the system operator is permitted to disconnect intermittent energy (CRE, 2009). Note that this rate of 30\% was achieved for a few hours in 2012 in Reunion and in Guadeloupe, resulting in the disconnection of certain facilities of PV production.

The forecast of these fluctuation sources across the concerned islands should allow a better control of the availability of renewable energy production, and thereby reduce the pressure on the balance of supply/demand. Moreover associated with power storage unit (batteries or STEP, for example) will help providing various services to the power system, from ancillary services (adjusting voltage, frequency) to smoothing peak hours. The forecast of fluctuation sources will contribute to the optimization of the design and the use of these storage units.

Generally, the PV production forecast is classified into 2 categories: the day ahead (DA) forecast and the hour ahead (HA) forecast, depend on the domain of application (IEA, 2013).

- $\quad$ The day ahead (DA) forecast is usually based on the numerical weather prediction models. They are dynamical equations that predict the evolution of the atmosphere up to several days ahead from initial conditions. From the forecast of weather condition, the output power 
of PV can be estimated (Beyer HG et al., 2009), (Lorenz E et al., 2008), (Traunmüller W \& Steinmaurer G., 2010).

- The hour ahead (HA) forecast is usually based on stochastic learning techniques. The underlying assumption of these techniques is that future value of PV production can be predicted by training the algorithms with historical data (Fernandez-Jimenez et al., 2012), (Pedro \& Coimbra, 2012), (Mandal et al., 2012).

To generate a prediction of the PV production using stochastic learning techniques, it is necessary to have historical data. These data are used for the learning phase of forecast models of PV production at the studied site (IEA, 2013).

In the literature, several studies have been conducted on the methodology for the forecast of PV generation (Shi et al., 2012), (Krömer et al., 7-11 July 2012), (Lorenz et al., 2012). The authors generally use two historical years: one year for training the model and another year for the test phase. In the literature, the analysis of the minimum duration for the phases of test and training data is little documented.

The proposed study will determine the minimum of historical experimental data necessary to achieve a high accuracy forecast, which can be quantified by a set of several statistical error indicators. There are some works in other areas that focus on this problem (Fine \& Turmon, 1994), (Thirumalainambi, 2003), (Cui et al., 2004) but a study on the prediction of PV generation, to our knowledge, is not yet performed.

There are two major factors that affect the time required for the collection of historical data, they are the climatic conditions at the PV site and the statistical model used for the forecast.

The climatic conditions at the PV site affects the level and the type of data fluctuation. The more fluctuate the data is, the more they are difficult to predict, i.e.: the error on the forecast is higher. Therefore, the duration of the data collection is supposed to be longer. In this study, we 
investigate the influence of climatic conditions on the historical data necessary for a forecast of $\mathrm{PV}$ production by comparing two sites of $\mathrm{PV}$ generation with very different climatic conditions: one in Lille, in northern France and the other one in Guadeloupe, in the Caribbean.

The forecasting model also has a large influence on the duration required for the collection of historical data. There are simple forecasting models that requires a few data for the learning phase. The more complex the forecasting models is, the more historical data is needed but the result is often more accurate.

In this study, we will compare some of the most popular statistical models in forecasting PV production: Artificial Neural Network (ANN) (Yona et al., 2007), (Fernandez-Jimenez et al., 2012), (Mandal et al., 2012), Multivariate Polynomial Model (MPM) (Dazhi, 2012), (IEA, 2008) and the Scaled Persistence Model (IEA, 2013).

\section{Input data and site description}

In this paper, we will use PV production at time $(h)$ and two exogenous inputs: the cloud cover and the air temperature, also at time $(h)$, to forecast the PV production at time $(h+1)$.

For each hour $(h)$ considered as the beginning time of the forecasting, the input vectors are given by:

$$
x(h)=\left[N(h) ; T_{a}(h) ; P_{m}(h)\right]
$$

Where: $\quad-N(h)$ is the cloud cover measured at time (h)

- $T_{a}(h)$ is the ambiance temperature measured at time (h)

- $P_{m}(h)$ is the average output power produced by the PV system in the previous 60 minutes respective to the h-hour

a. Data measured in Guadeloupe, tropical climate

The PV system installed in Guadeloupe $\left(16^{\circ} 14^{\prime} 36.0^{\prime \prime} \mathrm{N} 61^{\circ} 33^{\prime} 25.9^{\prime \prime} \mathrm{W}\right)$ has 832 membrane PV modules of $136 \mathrm{Wp}$ each, which makes a total of $113 \mathrm{kWc}$. 
The system consists of two inverters. The data logging of PV output power (in W) is integrated in these inverters (collected every $5 \mathrm{~min}$ ). The two exogenous inputs: cloud cover (in octa) and air temperature (in ${ }^{\circ} \mathrm{C}$ ) are measured every hour by the weather station at the airport nearby (Raizet Airport) by Meteo France. As during the night, the forecast is not necessary because the output power of PV is zeros, the study takes into account only the data between 7a.m and 17p.m every day.

The average output power of PV in every hour is calculated from the measurement every 5 minutes of the inverters:

$$
P_{m}(h)=\frac{1}{12} \sum_{t=h-55 \min }^{h} P(t)
$$

The forecast models will be studied with a varying training period from one month to one year (365 days) and a testing period of 331 days. The output power of the PV system at time $(h+1)$, $P_{m}(h+1)$ will be predicted from three inputs: $N(h), T_{a}(h)$ and $P_{m}(h)$.

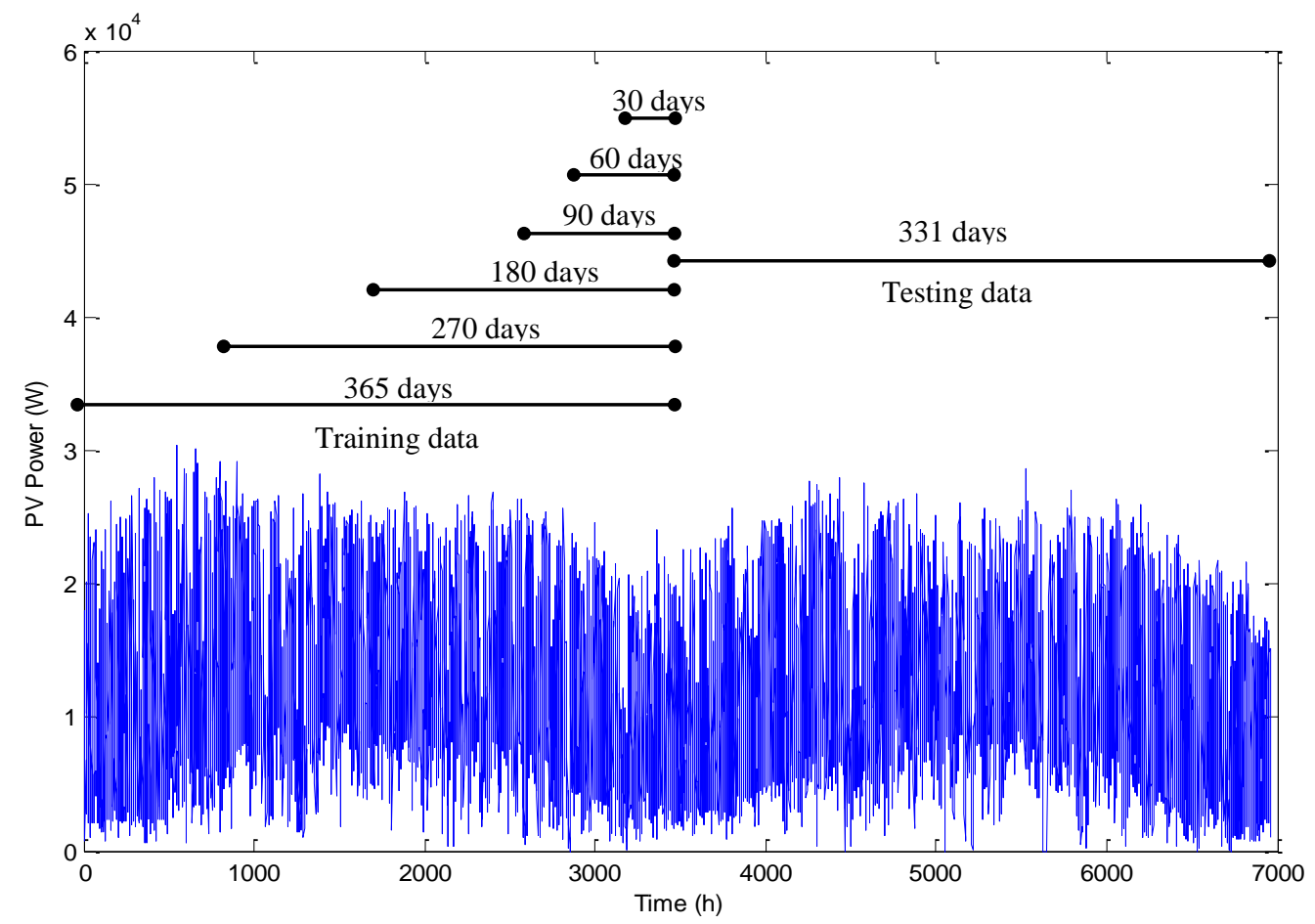


b. Data measured in Lille, temperate climate

The installation of a 93kWc PV system in Lille $\left(50^{\circ} 38^{\prime} 58.7^{\prime \prime} \mathrm{N} 3^{\circ} 09^{\prime} 04.3^{\prime \prime E}\right)$ consists of 452 panels. Among these panels, 376 modules have an inclination of $3^{\circ}$ and the inclination of the rest is $60^{\circ}$.

The system consists of 31 inverters. The data logging of PV output power (in W) is integrated in these inverters (collected every $10 \mathrm{~min}$ ). The two exogenous inputs: cloud cover (in octa) and ambiance temperature (in ${ }^{\circ} \mathrm{C}$ ) are measured every hour by the weather station at the airport

112 nearby (Lesquin Airport) by Meteo France. As the sun rise is later in Lille, the study takes into

113 account only the data between 10a.m and 17p.m every day to avoid the zero output power of 114 PV during the night.

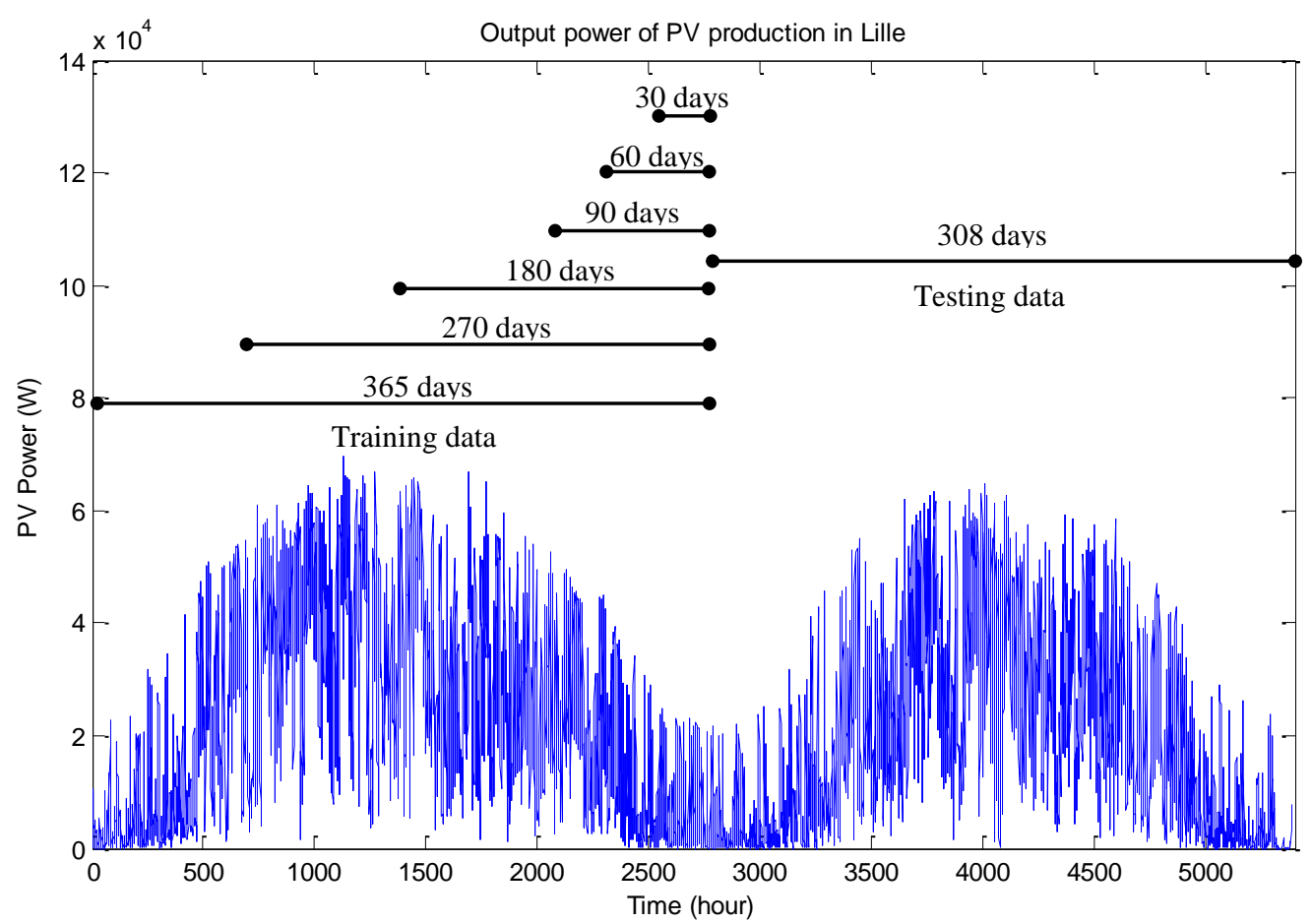

Figure 2. Output power for training and testing in Lille

117 The average output power of PV in every hour is calculated from the measurement every 10

118 minutes of the inverters: 


$$
P_{m}(h)=\frac{1}{6} \sum_{t=h-50 \min }^{h} P(t)
$$

119 The forecast models will be studied with a varying training period from one month to one year

120 (365 days) and a testing period of 308 days. The output power of the PV system at time $(h+1)$,

$121 P_{m}(h+1)$ will be predicted from three inputs: $N(h), T_{a}(h)$ and $P_{m}(h)$.

c. Evaluating the quality of forecast

The precision of the forecast will be evaluated using the following statistical error indicators:

- $\quad$ Normalized mean bias error $(\%)$

$$
N M B E=\frac{1}{M} \frac{\sum_{h=1}^{M} P_{m}(h)-\tilde{P}_{m}(h)}{\max \left(P_{m}\right)-\min \left(P_{m}\right)} \times 100
$$

- $\quad$ Normalized mean absolute error (\%)

$$
N M A E=\frac{1}{M} \frac{\sum_{h=1}^{M}\left|P_{m}(h)-\tilde{P}_{m}(h)\right|}{\max \left(P_{m}\right)-\min \left(P_{m}\right)} \times 100
$$

- $\quad$ Normalized root -mean-square error $(\%)$

$$
\text { NRMSE }=\frac{\sqrt{\frac{1}{M} \sum_{h=1}^{M}\left(P_{m}(h)-\tilde{P}_{m}(h)\right)^{2}}}{\max \left(P_{m}\right)-\min \left(P_{m}\right)} \times 100
$$

129 Where: $\quad-P_{m}(h)$ is the average output power produced by the PV system at hour $(h)$

\section{The forecasting models}

133 In this research, the forecasting models will take into account the data of PV production at time $(h), P_{m}(h)$ and two exogenous inputs: the cloud cover $N(h)$ and the air temperature $T_{a}(h)$, also 
at time $(h)$, to predict the PV production at time $(h+1)$. As the PV production depends on the position of the sun in the day while others input variables does not, a normalization is needed to eliminate this subordination. The input of the PV production at time $(h)$ becomes now $\bar{P}_{m}(h)$,

138 the normalized value of the PV production with respect to the maximum value at time $(h)$, $P_{\max }(h)$.

The absolute value of the PV output power prediction is then obtained by multiplying this

141 normalized value with the maximum value of PV production at time $(h+1), P_{\max }(h+1)$. This

142 maximum value can be evaluated from the $G H I_{\max }$ curve with the following equation:

$$
P_{\max }=\frac{G H I_{\max }}{\max \left(G H I_{\max }\right)} \cdot P V_{\text {installed }}
$$

143 The Global Horizontal Irradiance (GHI) is the total amount of shortwave radiation received

144 from above by a surface horizontal to the ground, which consists of the direct irradiance and 145 the diffuse irradiance. The $\mathrm{GHI}_{\max }$ is the GHI calculated in the condition of clear sky, using the 146 Kasten clear sky models. (Kasten, 1980)

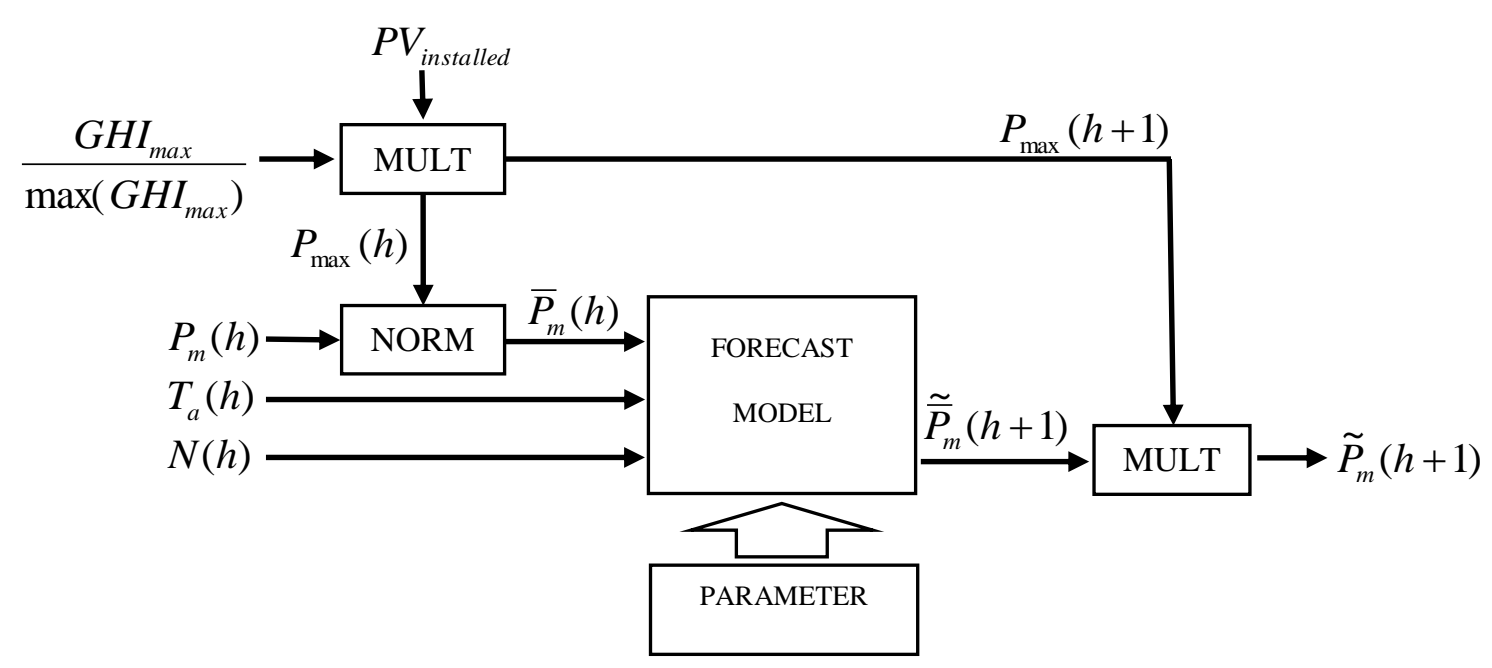
Figure 3. General process of the PV output power forecast 
The Artificial Neural Network used in this research is a feedforward neural network for nonlinear regression with 1 hidden layer. The choice of the number of neurons in the hidden layer is a complicated issue. In this paper, a value of 4 is chosen based on several researches in literature (Blum, 1992), (Swingler, 1996), (Berry \& Linoff, 1997), (Boger, 1997). The Artificial Neural Network will be trained by the historical data with the supervised learning technique, using the Levenberg-Marquardt algorithm (Seber \& Wild., 2003).

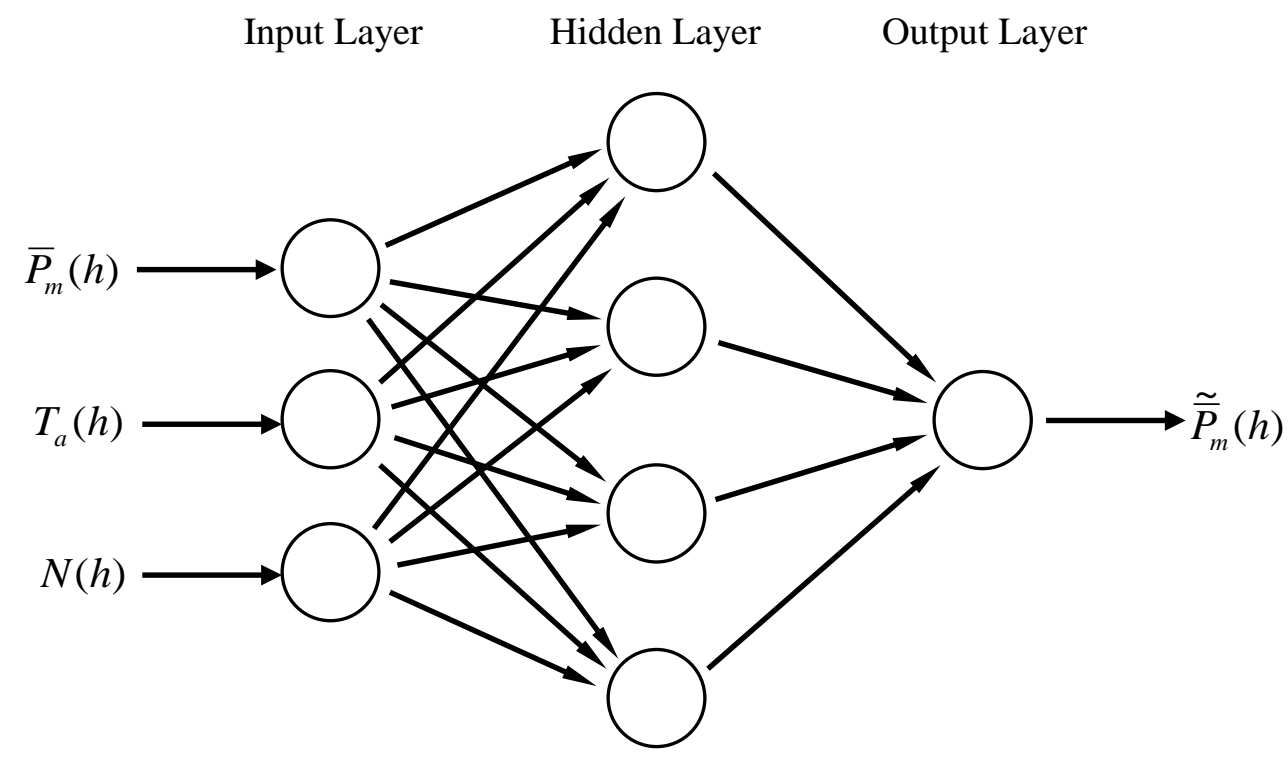

\section{b. Multivariate Polynomial Model}

The polynomial models are very popular due to their simplicity in form, their well-known and general, and in PV production forecasting in particular (Dazhi, 2012), (IEA, 2008). 

takes into account several input variables is proposed to improve the accuracy of the prediction of PV output power. The output prediction of the normalized value at time $(h+1)$ is a multivariate polynomial function of the input variables:

$$
\begin{aligned}
& \tilde{\bar{P}}_{m}(h+1)=b_{1} \cdot \bar{P}_{m}(h) \cdot N(h) \cdot T_{a}(h)+b_{2} \cdot \bar{P}_{m}(h) \cdot N(h)+b_{3} \cdot \bar{P}_{m}(h) \cdot T_{a}(h)+b_{4} \cdot N(h) \cdot T_{a}(h) \\
& +b_{5} \cdot \bar{P}_{m}(h)+b_{6} N(h)+b_{7} T_{a}(h)+b_{8}
\end{aligned}
$$
deviations:

$$
S(b)=\sum_{h=1}^{M}\left[\bar{P}_{m}(h)-\widetilde{\bar{P}}_{m}(h)\right]^{2}
$$

\section{c. Persistence Model}

The persistence model is based on a simple rule: the output value of the predicted variable at $(h+1)$ is equal to its value at $(h)$. The advantage of this technique is that it does not need to be trained by a series of historical data, however the accuracy of the forecast is not high.

In this paper, the Scaled Persistence Model is applied in order to reduce the forecasting error. This model is applied on the normalized value:

$$
\widetilde{\bar{P}}_{m}(h+1)=\bar{P}_{m}(h)
$$




\section{Results}

In this section, we will analyze the influence of the duration of training data on the forecasting

183 error. The parameters of the forecast model (Artificial Neural Network and Multivariate Polynomial Model) will be estimated using the historical data in 30 days, 60 days, 90 days, 180 days, 270 days and 365 days. Then, the model will be tested on a duration of 331 days (Guadeloupe) and 308 days (Lille). Due to its characteristic, the Scaled Persistence Model does not require any historical data, therefore, it will be tested directly with the testing data.

\subsection{Case of Guadeloupe}

The Table 1 and the Figure 5 show the evolution of the forecast error with different training duration in Guadeloupe.

Table 1. The evolution of the forecast error with different training duration (Guadeloupe)

\begin{tabular}{|c|c|c|c|}
\hline \multicolumn{4}{|c|}{ NMBE } \\
\hline Duration of training data & $\begin{array}{c}\text { Artificial Neural } \\
\text { Network }\end{array}$ & $\begin{array}{c}\text { Multivariate } \\
\text { Polynomial Model }\end{array}$ & $\begin{array}{c}\text { Scaled } \\
\text { Persistence Model }\end{array}$ \\
\hline 30days x 10 samples & $1.74 \%$ & $-0.87 \%$ & \multirow{6}{*}{$0.79 \%$} \\
\hline 60days x 10 samples & $0.22 \%$ & $-1.41 \%$ & \\
\hline 90days x 10 samples & $-0.62 \%$ & $-0.61 \%$ & \\
\hline 180days x 10 samples & $-0.30 \%$ & $-0.34 \%$ & \\
\hline 270days x 10 samples & $0.27 \%$ & $0.27 \%$ & \\
\hline 365days x 10 samples & $0.67 \%$ & $0.60 \%$ & \\
\hline \multicolumn{4}{|c|}{ NMAE } \\
\hline 30days x 10 samples & $9.90 \%$ & $10.06 \%$ & \multirow{6}{*}{$9.60 \%$} \\
\hline 60days x 10 samples & $9.32 \%$ & $9.51 \%$ & \\
\hline 90days x 10 samples & $9.23 \%$ & $9.26 \%$ & \\
\hline 180days x 10 samples & $9.13 \%$ & $9.21 \%$ & \\
\hline 270days x 10 samples & $9.07 \%$ & $9.10 \%$ & \\
\hline 365days x 10 samples & $9.22 \%$ & $9.19 \%$ & \\
\hline \multicolumn{4}{|c|}{ NRMSE } \\
\hline
\end{tabular}




\begin{tabular}{|c|c|c|c|}
\hline 30days x 10 samples & $13.22 \%$ & $13.00 \%$ & \multirow{6}{*}{$13.07 \%$} \\
\hline 60days x 10 samples & $12.36 \%$ & $12.21 \%$ & \\
\hline 90days x 10 samples & $12.15 \%$ & $11.97 \%$ & \\
\hline 180days x 10 samples & $11.95 \%$ & $11.94 \%$ & \\
\hline 270days x 10 samples & $11.90 \%$ & $11.86 \%$ & \\
\hline 365days x 10 samples & $12.09 \%$ & $11.93 \%$ & \\
\hline
\end{tabular}

14,00

13,50

13,00

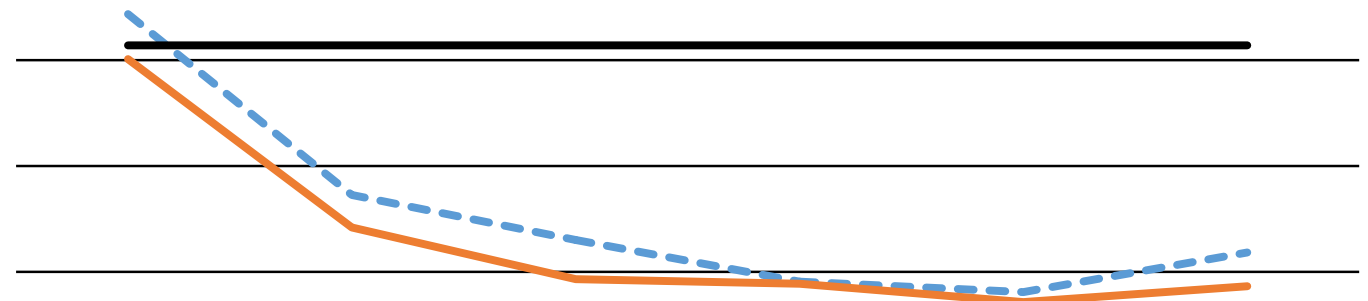

11,50

11,00

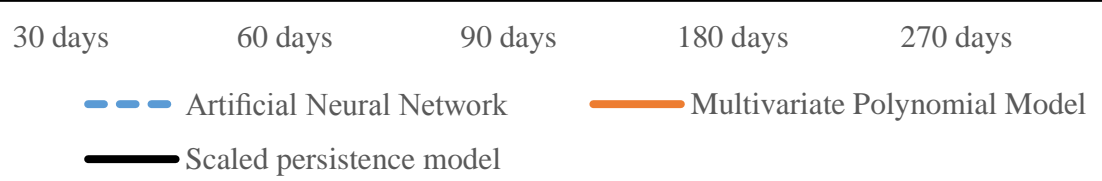

Figure 5. The evolution of the NRMSE (\%) with different training duration (Guadeloupe)

195 The value of the bias error NMBE allows to evaluate the tendency of the prediction model to 196 underestimate or overestimate the PV output power. In this study, the NMBE is relatively small 197 with all 3 methods and oscillating around the zero. However, the variation of the NMBE does 198 not follow any certain rule (Table 1).

199 The NMAE is used to measure how close the forecasts or predictions are to the eventual 200 outcomes. As presented in the Table 1, from the training data of more than 1 month, the NMAE 201 of the Artificial Neural Network and the Multivariate Polynomial Model is lower than the 
Scaled Persistence Model. The NMAE of the Multivariate Polynomial Model is slightly higher than that of the Artificial Neural Network.

The Root-Mean-Square Error (RMSE) is a frequently used measure of the differences between value (Sample and population values) predicted by a model or an estimator and the values actually observed. Basically, the RMSE represents the sample standard deviation of the differences between predicted values and observed values. The NRMSE is the RMSE divided by the range of observed values of the variable being predicted. In literature, the NRMSE is mostly preferred than the NMAE because this indicator contain both information of the bias and the variance of the prediction.

As the Scaled Persistence Model does not require the historical data, the forecasting error of this model is usually the highest among the three. However, it is still lower than the forecasting error of Artificial Neural Network with only 1 month of training data. Generally, if the duration of the collected data is shorter than 1 month, it is advisable to use the Scaled Persistence Model. From more than one month of training data, the Artificial Neural Network and the Multivariate Polynomial Model are more accurate. The forecasting error reduce rapidly from more than $13 \%$ to less than $12 \%$ with the training data of 3 months (Multivariate Polynomial Model) or of 6 months (Artificial Neural Network). With the Multivariate Polynomial Model, the difference of data collection.

With the training data of 365 days, the forecast error is slightly higher than that given by the training data of 270 days, which is not coincident with the tendency of reduction of the forecast error with longer training data. This contradiction could be explained by a hypothesis that the training data of the period of 3 months which has just been added to the training data may disturb the forecast model. To verify this hypothesis, another forecast is implemented using the 
training data from the first 9 months of the training year (see Figure 1). The result shows that the forecast error in both models is higher than that using the training data from the last 9 months (12.21\% with Artificial Neural Network and $12.01 \%$ with Multivariate Polynomial Model). Therefore, the hypothesis can be confirmed.

\subsection{Case of Lille}

The Table 2 and the Figure 6 show the evolution of the forecast error with different training duration in Lille.

Apart from the Scaled Persistence Model, which does not require the historical data, the forecast error of the Artificial Neural Network and the Multivariate Polynomial Model is high with the training data from 1 to 3 months due to the seasonal effect of Lille. With this effect, the right parameters of the forecast model cannot be evaluate from the training data of 1 to 3 months. However, from 6 months and above, the forecast error is reduced significantly (from $12.71 \%$ to $10.69 \%$ with Multivariate Polynomial Model). The reduction starts from 6 months of training data, not from 1 year, due to the symmetry of the PV production of Lille in a year (see Figure 2). The difference of forecast error between the training duration of 6 months, 9 months and 1 year in Lille is negligible. The training period could be finished after 6 months of data collection.

Table 2. The evolution of the forecast error with different training duration (Lille)

\begin{tabular}{|c|c|c|c|}
\hline \multicolumn{3}{|c|}{ NMBE } \\
\hline Duration of training data & $\begin{array}{c}\text { Artificial Neural } \\
\text { Network }\end{array}$ & $\begin{array}{c}\text { Multivariate } \\
\text { Polynomial Model }\end{array}$ & $\begin{array}{c}\text { Scaled } \\
\text { Persistence Model }\end{array}$ \\
\hline 30days x 10 samples & $-5.62 \%$ & $-7.65 \%$ & \\
\cline { 1 - 2 } 60days x 10 samples & $-9.35 \%$ & $-6.78 \%$ & \multirow{2}{*}{$-0.09 \%$} \\
\hline 90days x 10 samples & $-4.45 \%$ & $-4.08 \%$ & \\
\hline 180days x 10 samples & $-0.24 \%$ & $-0.23 \%$ & \\
\hline
\end{tabular}




\begin{tabular}{|c|c|c|c|}
\hline 270days x 10 samples & $-0.73 \%$ & $-0.81 \%$ & \\
\hline 365days x 10 samples & $-0.76 \%$ & $-0.81 \%$ & \\
\hline \multicolumn{4}{|c|}{ NMAE } \\
\hline 30days x 10 samples & $13.02 \%$ & $11.43 \%$ & \multirow{6}{*}{$7.44 \%$} \\
\hline 60days x 10 samples & $12.17 \%$ & $10.90 \%$ & \\
\hline 90days x 10 samples & $10.54 \%$ & $9.36 \%$ & \\
\hline 180days x 10 samples & $7.63 \%$ & $7.62 \%$ & \\
\hline 270days x 10 samples & $7.65 \%$ & $7.71 \%$ & \\
\hline 365days x 10 samples & $7.62 \%$ & $7.75 \%$ & \\
\hline \multicolumn{4}{|c|}{ NRMSE } \\
\hline 30days x 10 samples & $18.39 \%$ & $16.21 \%$ & \multirow{6}{*}{$11.37 \%$} \\
\hline 60days x 10 samples & $16.07 \%$ & $15.34 \%$ & \\
\hline 90days x 10 samples & $14.79 \%$ & $12.71 \%$ & \\
\hline 180days x 10 samples & $10.83 \%$ & $10.69 \%$ & \\
\hline 270days x 10 samples & $10.62 \%$ & $10.63 \%$ & \\
\hline 365days x 10 samples & $10.53 \%$ & $10.63 \%$ & \\
\hline
\end{tabular}

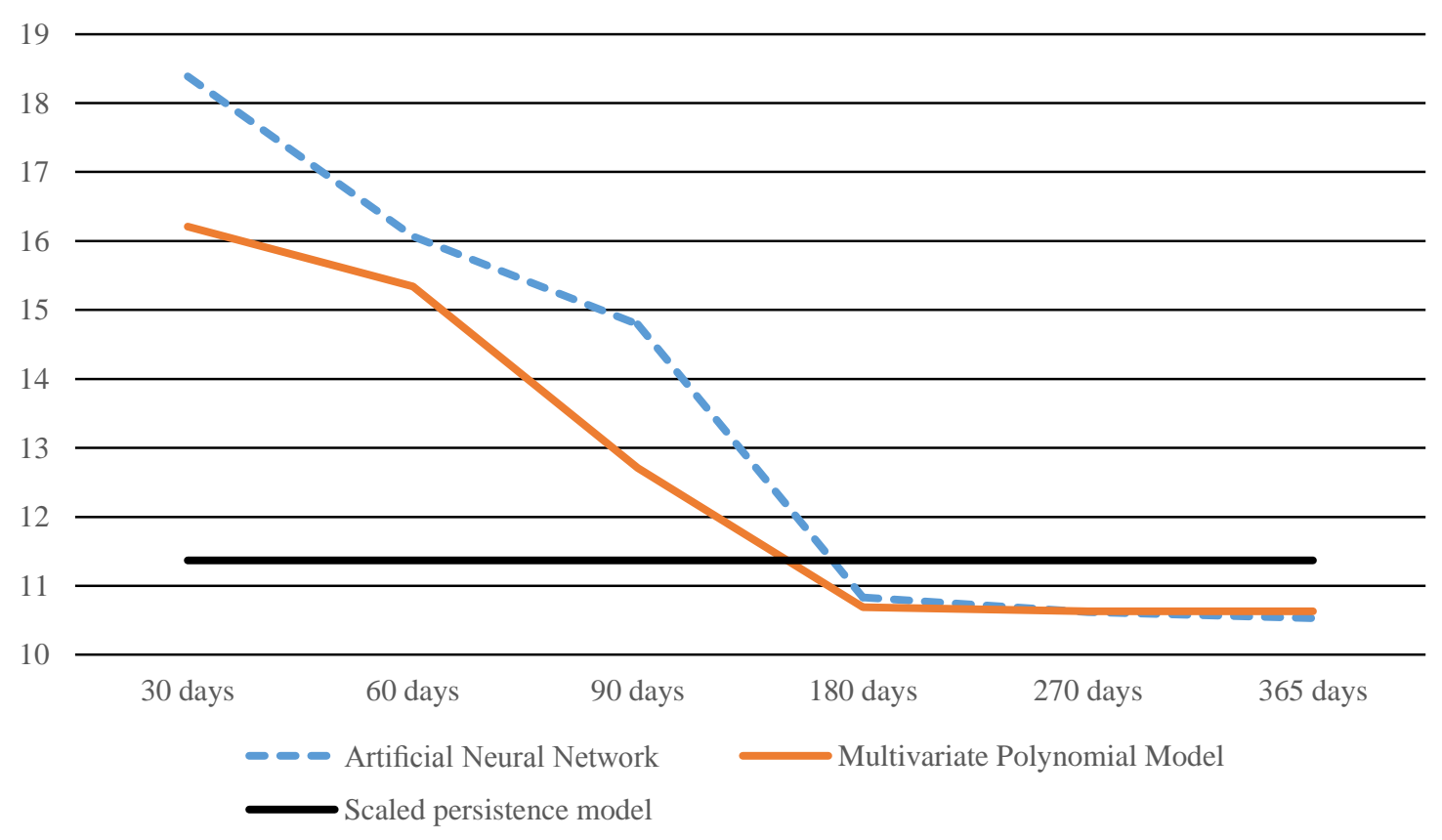

Figure 6. The evolution of the NRMSE (\%) with different training duration (Lille) 
We can observe that the duration of data collection required to have a good forecast in Lille is

248 higher than the duration of data collection needed in Guadeloupe (6 months compared to 3

249 months). However, the forecast error in Lille is smaller (10.69\% compared to $11.97 \%)$.

\subsection{Analysis and recommendations}

Among the 3 models, the Scaled Persistence Model does not require the historical data, therefore the forecast can be obtained directly without training period. However, the quality of forecast is not high. In the beginning, this model can compete with the others 2 forecast models but from 2 months of training data (Guadeloupe) and from 6 months of training data (Lille), the quality of the forecast by these model is much better than that of the Scaled Persistence Model.

The Artificial Neural Network and the Multivariate Polynomial Model have the same evolution of forecast error due to the fact that both of these models use the Levenberg-Marquardt algorithm as core learning technique. The Multivariate Polynomial Model has a better forecast quality than the Artificial Neural Network. In Guadeloupe, the Artificial Neural Network needs 6 months of training data to acquire the forecast error lower than $12 \%$ while the Multivariate Polynomial Model needs only 3 months to go under this level. Another advantage of the Multivariate Polynomial Model is the simplicity and the transparency of the model. This is an analytical model, it means that the relation between the predicted value and the input variables can be represented in the form of an equation, different from the Artificial Neural Network, where this relation can only be represented by a black box.

As presented in the Figure 1 and the Figure 2, the PV production of Guadeloupe and Lille has very different characteristics. In Lille, there is a seasonal effect that there is not in Guadeloupe. However the PV production of Lille is less fluctuant than that of Guadeloupe. Therefore, to obtain a good quality forecast, the model of Lille needs a longer duration of training data (6 
months instead of 3 months). But once the model is trained, it provides a better performance than that of Guadeloupe.

272

\section{Conclusions}

This paper focus on the necessary duration of data collection to have a quality forecast of PV production for two climatic conditions: a temperate and a tropical weather conditions. In order to investigate this issue, the study is implemented on $2 \mathrm{PV}$ installations: the first one in Guadeloupe, the second in Lille; using 3 different forecast models: the Scaled Persistence Model, the Artificial Neural Network and the Multivariate Polynomial Model.

The results show that with the temperate climate such as Lille, where the seasonal effect existed, a training duration of at least 6 months is needed to acquire a high accuracy forecast for PV generation instead of 3 months with the tropical climate at Guadeloupe. However, once the model is trained, the performance is better (error of $10.69 \%$ at Lille compared to $11.97 \%$ at Guadeloupe).

This research proposes to use the Scaled Persistence Model to forecast the PV output power during the data collection as this model does not require the historical data. Once the data collection phase is finished, the Multivariate Polynomial Model could be applied in order to provide a better accuracy. With the application of $\mathrm{PV}$ output forecast, the exploitation of $\mathrm{PV}$ becomes more efficient, reducing the risk of power outages and improving the reliability of power supply.

\section{$\underline{\text { References }}$}

Berry, M.J.A. \& Linoff, G., 1997. Data Mining Techniques. NY: John Wiley \& Sons.

Beyer HG et al., 2009. Report on Benchmarking of Radiation Products. Report under contract no. 038665 of MESoR.

Blum, A., 1992. Neural Networks in C++. NY: Wiley. 
Boger, Z..a.G.H., 1997. Knowledge extraction from artificial neural network models. In IEEE Systems, Man, and Cybernetics Conference. Orlando, FL, 1997.

CRE, 2009. Cahier des charges de l'appel d'offresportant sur des installations au sol de production d'électricitéà partir de l'énergie solaire. Ministère de l'Ecologie, de l'Energie, du Développement durable et de l'Aménagement du territoire.

Cui, Y.-J., Davis, S., Cheng, C.-K. \& Bai, X., 2004. A study of sample size with neural network. In Proceedings of 2004 International Conference on Machine Learning and Cybernetics., 2004.

Dazhi, Y., 2012. Solar modeling and forecast. A report submitted to the department of electrical and computer engineering and the examination committee of national university of Singapore.

Do, M.T., Sprooten, J., Clenet, S. \& Robyns, B., 2010. Influence of wind turbines on power system reliability through probabilistic studies. In Innovative Smart Grid Technologies Conference Europe (ISGT Europe)., 2010.

Do, M.T., Sprooten, J., Clenet, S. \& Robyns, B., 2011. Reliability evaluation of power system with large-scale wind farm integration using first-order reliability method. In Proceedings of the 2011-14th European Conference on Power Electronics and Applications., 2011.

Ernst, B., Reyer, F. \& Vanzetta, J.., 2009. Wind power and photovoltaic prediction tools for balancing and grid operation. In CIGRE/IEEE PES Joint Symposium Integration of Wide-Scale Renewable Resources Into the Power Delivery System., 2009.

Fernandez-Jimenez, L.A. et al., 2012. Short-term power forecasting system for photovoltaic plants. Renew. Energy, pp.311-317.

Fine, T.L. \& Turmon, M.J., 1994. Sample Size Requirements of Feedforward Neural Network. In Advances in Neural Information Processing Systems., 1994.

IEA, 2008. Performance prediction of grid connected photovoltaic systems using remote sensing.

IEA, 2013. Photovoltaic and Solar Forecasting: State of the Art Report. 
Kasten, F., 1980. A simple parameterization of two pyrheliometricformulae for determining the Linke turbidity factor. Meteorol. Rundsch., 33, pp.124-127.

Krömer, P. et al., 7-11 July 2012. Evolutionary Prediction of Photovoltaic Power Plant Energy

Production. In In Proceedings of International Conference on Genetic and Evolutionary Computation.

Philadelphia, PA, USA, 7-11 July 2012.

323

324

Lorenz E et al., 2008. Qualified Forecast of Ensemble Power Production by Spatially Dispersed GridConnected PV Systems. In Proceedings of the 23rd European Photovoltaic Solar Energy Conference and Exhibition., 2008.

Lorenz, E., Heinemann, D. \& Kurz, C., 2012. Local and regional photovoltaic power prediction for large scale grid integration: Assessment of a new algorithm for snow detection. Prog. Photovolt. Res. Appl., pp.760-769.

Mandal, P. et al., 2012. Forecasting power output of solar photovoltaic system using wavelet transform and artificial intelligence techniques. Procedia Comput. Sci., pp.332-337.

Pedro, H.T.C. \& Coimbra, C.F.M., 2012. Assessment of forecasting techniques for solar power production with no exogenous inputs. Solar Energy, 86, pp.2017-2028.

Seber, G.A.F. \& Wild., a.C.J., 2003. Nonlinear Regression. Hoboken, NJ: Wiley-Interscience.

Shi, J. et al., 2012. Forecasting power output of photovoltaic systems based on weather classification and support vector machines. IEEE Trans. Ind. Appl., pp.1064-1069.

Swingler, K., 1996. Applying Neural Networks: A Practical Guide. London: Academic Press.

Thirumalainambi, R.a.B.J., 2003. Training data requirement for a neural network to predict aerodynamic coefficients. In Proc. SPIE 5102, Independent Component Analyses, Wavelets, and Neural Networks. Orlando, FL, 2003. 
340 Traunmüller W \& Steinmaurer G., 2010. Solar irradiance forecasting, benchmarking of different 341 techniques and applications of energy meteorology. In Proceedings of the EuroSun 2010 conference. 342 Graz, Austria, 2010.

343 Yona, A. et al., 5-8 November 2007. Application of Neural Network to One-day-ahead 24 hours 344 Generating Power Forecasting for Photovoltaic System. In In Proceedings of the International 345 Conference on Intelligent Systems Applications to Power Systems. Kaohsiung, Taiwan, 5-8 November 3462007. 